\title{
Personal Image Types and Preference Analysis of Male Celebrities in the Silver Generation
}

\author{
Ae-Kyung Kim \\ Institue of Continuing Education, Tongmyong University, Busan, Korea
}

Corresponding author: Ae-Kyung

Kim, Institue of Continuing Education,

Tongmyong University, 428, Sinseon-ro,

Nam-gu, Busan 48520, Korea

Tel.: +82 516293542

Fax: +82 516217714

Email: yeskak@daum.net

Received October 7, 2019

Revised November 18, 2019

Accepted November 27, 2019

Published December 30, 2019

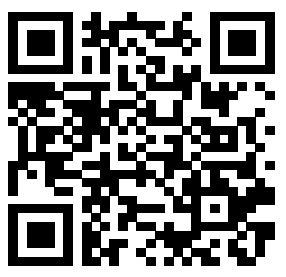

\begin{abstract}
Purpose: This study classifies types of personal image and examines the characteristics of each type through personal image evaluation of South Korean silver generation male celebrities. This study aims to understand the personal image of silver generation male celebrities and to use the gathered information as basic data to develop an image making strategy by assessing personal image preference for silver generation. Methods: Fifty male celebrities, from the ages $55-65$, were selected as the subjects of evaluation. The questionnaire consisted of 19 adjective pairs and preference items. The data was collected from March 18 to April 12, 2019, and the final data, gathered from 200 participants, was used. Results: First, the hierarchical structure of the personal image of silver generation male celebrities is indicated by an intelligent and a warm image. Second, there are four types of personal images of silver generation male celebrities, which are as follows: goodimpression image, sociable image, charismatic image, and quiet image. Third, Moon Se Lee has the most favorable male celebrity personal image among 20-year-olds, and Hyung Gi Cho's image seems to be the most disliked. Conclusion: Implementing personal images based on the analyzed characteristics of each type will enable one to plan their personal image. The top 20 most favored were ranked highest on the basis of attractiveness and good impression, sociable, and soft images, while the lowest were ranked on the basis of their unattractiveness and bad impression, unsociable, and non-individual images. It would be effective to use this result as a strategy to target 20-year-olds in the necessary areas.
\end{abstract}

Keywords: Personal image, Types, Preference, Silver generation, Male celebrities

\section{Introduction}

사회구조의 다양한 변화와 더불어 과학기술의 발달, 의학의 발 전 등으로 사람의 수명이 연장됨으로 인해(Kim \& Lee, 2009) 노 년의 삶의 형태가 변화되고 있다.

현대에는 외모가 청, 장년의 시기에만 중요한 요소로 작용하는 것이 아니라 노년에도 외모는 개인적, 사회적으로 다양한 영역에 서 장점으로 영향력을 발휘하고 있다. 이러한 가치관의 흐름 속 에서 개성을 발견하고 추구하는 것이 바람직하며, 개성있는 이미 지를 표출하기 위해 외모 중에서도 얼굴의 영향이 크게 작용함으 로 얼굴에서 드러나는 이미지에 초점을 맞출 필요가 있다(Kim, 2012). 퍼스널 이미지는 개인의 특성이 타인에게 지속적인 정보 로 구성되어 총체적으로 느껴지는 것이다. 그러므로 이미지를 구
축하고 표현하는 것은 인간관계형성에 도움을 줄 것이며, 사회적 역할이 복잡해지고 각자의 개성이 두드러짐에 따라 개인의 정확 한 이미지를 파악하는 것이 바람직하다(Oh \& Km, 2017). 외모 와 관련된 연구를 살펴보면, 계층에 따른 헤어스타일을 상류층에 서 40,50 대는 $2: 8$ 가르마를, 60 대는 올백스타일을, 중류층은 40 대 이상이 $1: 9$ 가르마와 $2: 8$ 가르마의 단정한 헤어를, 하류층은 짧은 숏 컷을 많이 하는 것으로 나타났다고 하였다(Lee \& Kim, 2012). 퍼스널 이미지의 관련 연구를 살펴보면, 60 대 얼굴의 이미 지 어휘를 도출한 연구에서 피곤해보이는, 무서운, 우울한, 날카 로운, 고집스러운 등이 두드러진 것은 60 대 얼굴이 굳어있는 표정 과 주름의 영향이라고 하였으며, 착한, 온화한 등의 이미지가 두 드러지는 것은 평가자가 선호하는 이미지의 영향이라고 하였다 (Kim, 2012). 55세 이상의 여성이 추구하는 자기 이미지는 품위 
있는, 젊어보이는, 세련된, 고상한, 우아한 이미지라고 하였으며, 이런 여성들은 화려한 이미지보다 품위있고 젊어보이면서 고상한 이미지를 추구한다고 하였다(Wee \& Sohn, 2001). 시니어 여성의 패션이미지 유형을 구분 짓는 속성은 품위성, 실용성, 개성, 유행 성, 젊음성으로 품위를 표현하거나 합리적이고 실용적인 측면을 고려한다고 볼 수 있으며, 유형의 분류는 개성추구 모던, 합리지 향 베이직, 편안함 추구 컨템포러리, 보수지향 엘레강스라고 하였 다(Kim et al., 2014). TV선거토론에서 정치 후보자의 비언어적 행위를 대상으로 후보자의 이미지를 유형화한 신뢰성 이미지, 리 더십 이미지, 역동성 이미지, 권위적 이미지를 투표의사와의 관계 를 분석한 것이다(Song, 2009). 이렇듯 이미지 관련 연구는 여성 대상이 다수이며, 남성을 대상으로 한 퍼스널 이미지 연구가 미흡 한 실정이다. 또한 실버세대라는 용어는 노년층을 달리 이르는 말 로 학문적으로 그 개념이 정립되어 있는 것은 아니나 노인의 흰머 리를 미화시켜 표현한 어휘로 1990 년대부터 보편적으로 사용되어 왔다(Oh, 2019). 우리나라의 경우 보편적인 퇴직연령이 55세로 신체적, 심리적 변화와 노화가 본격적으로 시작되는 이 시기를 기 준으로 실버세대로 분류하고 있으며(Jo \& Kim, 2009), 노인의 게 임 연구에서 50-59를 예비노인으로 정의하고 있다(Seo \& Kim,
2014). 그래서 이 논문에서는 실버세대 남자 유명인을 55-65세 를 대상으로 한정하였다. 실버세대를 대상으로 한 연구들은 실버 세대의 감성(Huh et al., 2012)연구와 여자 실버세대를 대상으로 (Kim, 2012; Kim \& Oh, 2014; Oh, 2019)한 연구가 대부분임 으로 남자 실버세대의 퍼스널이미지를 평가, 분석할 필요가 있다.

이 연구는 실버세대 남자 유명인을 대상으로 퍼스널이미지 평 가에서 유형을 분류하고 그 특성과 퍼스널 이미지에 영향을 미치 는 형용사 특성 및 남성 유명인의 이미지 순위를 알아보고자 한 다. 이 결과를 기반으로 실버세대 남성을 대상으로 하는 상품 개 발 및 이미지메이킹 전략의 기초자료로 활용 할 수 있을 것이다.

\section{Methods}

\section{1. 자극물 구성}

실버세대의 남자 유명인의 퍼스널 이미지를 평가하기 위해 자극물 구 성을 아래와 같이 실시하였다.

자극물 대상은 55 세에서 65 세까지의 남자 유명인을 2018년 5 월 20 일부터 5 월 21 일까지 중앙일보, 조선일보 홈페이지의 인물 검색하여 이

\section{Table 1. Personal Image types of male celebrities}

\begin{tabular}{|c|c|c|c|}
\hline Group & Male celebrities & Representative & Variable \\
\hline $\begin{array}{l}1(16) \\
\text { Good- impression } \\
\text { image }\end{array}$ & $\begin{array}{l}\text { Soo Bae Chul, Suk Hee Son, } \\
\text { Chang Wan Kim, Gap Soo Kim, } \\
\text { Sang Won Park, Yo Seob Hong, } \\
\text { Dong Geun Yu, Suk Woo Kang, } \\
\text { Young Kyu Park, Byeong Jin Ju, } \\
\text { Moon Se Lee, Mu Song Lee, } \\
\text { Ho Jin Cheon, Bo Seog Jeong, } \\
\text { Su Jong Choi, Byung Se Kim }\end{array}$ & & $\begin{array}{l}\text { - Good impression } \\
\text { - Bad impression } \\
\text { - Docile-Dread } \\
\text { - Warm-Cool } \\
\text { - Intellectual } \\
\text { - Non-intellectual }\end{array}$ \\
\hline $\begin{array}{l}2(10) \\
\text { Sociable image }\end{array}$ & $\begin{array}{l}\text { Jin A Tae, Hong Ryeol Lee, } \\
\text { Seung Hwan Song, Un Do Seol, } \\
\text { Seo Bum Hong, Kyoung Kyu Lee, } \\
\text { Han Wi Lee, Yang Rak Choi, Jae } \\
\text { Duk Sun Woo, Bong Won Lee }\end{array}$ & & $\begin{array}{l}\text { - Sociable-Unsociable } \\
\text { - Docile-Dread } \\
\text { - Warm-Cool } \\
\text { - Good impression } \\
\text { - Bad impression }\end{array}$ \\
\hline $\begin{array}{l}3(10) \\
\text { Charismatic image }\end{array}$ & $\begin{array}{l}\text { Min Sik Choi, Min Soo Choi, } \\
\text { Jae Bum Lim, Young Cheol } \\
\text { Kim, Young Don Lee, Jung } \\
\text { Woo Choi, Dong Jun Lee, } \\
\text { Si Min Yoo, Gwang Yeol } \\
\text { Jeon, Kyung Yeong Lee }\end{array}$ & & $\begin{array}{l}\text { - Charismatic-Uncharismatic } \\
\text { - Docile-Dread } \\
\text { - Strong-Weak } \\
\text { - Urban-Countrified }\end{array}$ \\
\hline $\begin{array}{l}4(14) \\
\text { Quiet image }\end{array}$ & $\begin{array}{l}\text { Beom Keun Cha, Han Gil Kim, } \\
\text { Sung Keun Moon, Myung Hoon } \\
\text { Jung, In Gwon Jeon, Sang Hoon } \\
\text { Choi, Jun Pyo Hong, Hee Do Lee, } \\
\text { Hyeong Gi Jo, Moon Sun Shin, } \\
\text { Kyu Chul Kim, Hyo Jung Lee, } \\
\text { Eung Soo Kim, Cheol Soo Ahn }\end{array}$ & & $\begin{array}{l}\text { - Quiet-Lively } \\
\cdot \text { Pushful-Passive } \\
\text { - Elegant-Unelegant }\end{array}$ \\
\hline
\end{tabular}




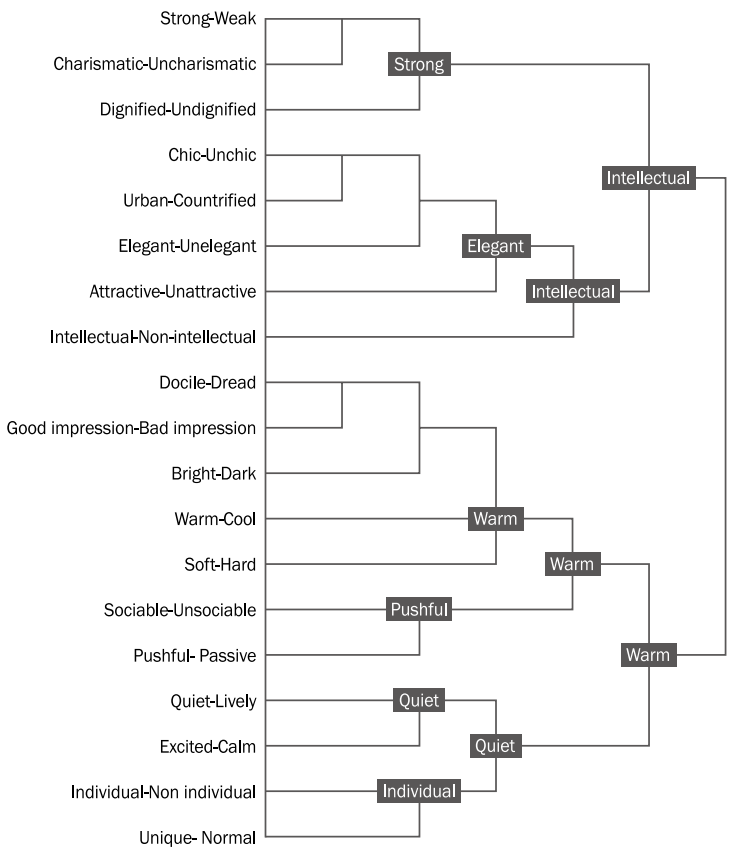

Figure 1. Image adjective hierarchy of male celebrities. Hierarchical combination process of male celebrities image adjectives.

중 인지도를 고려하여 50 명을 선정하였다. 설문지 평가를 위해 포털사 이트 및 연예 기사 등에서 각 남자 유명인의 사진을 각각 6 장씩 수집하 여, 시각적 오류를 줄이기 위해 배경을 제외하고 이미지맵으로 구성하 여 평가자에게 제시하였다.

\section{2. 설문지 구성 및 평가 방법}

이미지 평가는 일대일 대인면접의 형태로 실시하였다. 이미지 평가를 위해 선행연구(Oh, 2019; Kim \& Lee, 2009; Oh \& Lee, 2006)를 참조 하여 19 개의 형용사쌍을 구성하였고, 7 점 양극 의미미분척도를 사용하 였다. 그리고 남자 유명인에 대한 퍼스널 선호 이미지를 알아보기 위한 문항을 추가하였다.

자료 수집은 2019년 3월 18 일부터 4월 12 일까지 이루어졌으며 설문 대상은 외모에 관심이 많고, 평가에 있어 변별력 있는 집단인 20 대 225 명에게 실시하였고, 부적합한 자료를 제외한 최종 200 명의 자료를 분석 에 사용하였다.

수집된 자료의 분석은 SPSS 20.0 프로그램(BM, USA)을 활용하여 계층적 군집분석, 기술통계, $\mathrm{K}$-평균군집분석, 회귀분석을 사용하였다.

\section{3. 연구문제}

연구문제 1 . 실버세대 남자 유명인에 대한 퍼스널 이미지의 형
용사 구조를 분석한다.

연구문제 2. 실버세대 남자 유명인에 대한 퍼스널 이미지의 유 형을 분류하고 외형적 특성을 알아본다.

연구문제 3. 실버세대 남자 유명인에 대한 퍼스널 이미지의 선 호를 알아본다.

\section{Results and Discussion}

\section{1. 남자 유명인에 대한 퍼스널 이미지의 형용사 계층 구조}

남자 유명인에 대한 퍼스널 이미지의 형용사 계층구조를 알아 보기 위해 계층적 군집분석을 사용하여 이미지 형용사의 결합 과 정을 덴드로그램(Dendrogram)으로 분석하였다(Figure 1). 덴드 로그램은 SPSS 20.0 프로그램에서 계층적 군집 해법의 단계를 시 각적으로 표현한 것으로서 각 단계에서 조합되는 군집과 거리를 나타낸다.

덴드로그램의 가로 방향의 거리는 형용사 간의 유사성을 보여 주는 것으로 거리가 짧을수록 용어의 유사성이 큼을 나타낸다. 각 형용사들의 결합과정을 살펴보면, 가장 가까운 거리에서 결합된 것은 '강한-약한', '카리스마 있는-카리스마 없는' 것으로 남성 유 명인에 있어 강한 이미지와 카리스마 있는 이미지가 가장 유사한 의미임을 알 수 있다. 다음으로 '세련된-촌스러운', '도시적인-전 원적인'이 가까운 거리에서 결합되고, '온순한-무서운', '인상 좋 은-인상 나쁜'이 가까운 거리에서 결합되었다. 따라서 남성 유명 인에 있어 세련된 이미지와 도시적인 이미지가 유사한 의미를 갖 고, 온순한 이미지와 인상 좋은 이미지가 유사함을 알 수 있다.

'강한-약한'과 '당당한-당당하지 않는'이 결합되어 강한 이미지 가 대표되었고, '세련된-촌스러운'은 '우아한-우아하지 않는'과 결 합되고 다시 '매력적인-매력적이지 않는'과 결합되어 우아한 이미 지로 대표되고 다음 단계에서 '지적인-지적이지 않는'과 결합되어 지적인 이미지가 대표되었다.

'온순한-무서운'과 '밝은-어두운'이 결합되고 다시 '따뜻한-차 가운'과 '부드러운-딱딱한'이 결합되었고 다음 단계에서 '사교적 인-사교적이지 않는'과 '진취적인-진취적이지 않는'이 결합하여 따뜻한 이미지가 대표되어 나타났다.

'점잖은-발랄한'과 '들뜬-차분한'이 결합되고 '개성 있는-개성 없는'과 '특이한-평범한'이 결합되어 점잖은 이미지로 단계적으로 결합되었다. 강한 이미지와 지적인 이미지가 결합하여 지적인 이 미지로, 따뜻한 이미지와 점잖은 이미지가 결합하여 따뜻한 이미 지로 대별되어 최종적으로 남성 유명인의 이미지는 지적인, 따뜻 한 이미지로 나타났다.

\section{2. 남자 유명인의 퍼스널 이미지 유형화 및 외형적 특성}

남자 유명인의 퍼스널 이미지를 유형화하기 위해 군집 분석을 
실시한 결과 4군집으로 나타났다(Table 1). 각 군집 유형에 따른 외형적 특성은 아래와 같다.

군집1은 인상 좋은, 당당한, 따뜻한, 지적인 이미지가 대표되는 군집이다. 얼굴형은 타원형과 긴형이 위주이며, 윤곽이 각지지 않 고 부드러운 것이 특징이다. 눈썹은 두텁고 눈썹 산이 각진 형이 많고, 눈은 또렷하고 큰 편이다. 헤어스타일은 단정함을 기본으 로 옆 가르마와 앞머리를 세련되게 앞이마를 약간 내린 형태이며, 웃는 모습에서 인상 좋은 이미지를 부각시킨다. 슈트가 잘 어울리 며, 이문세, 박상원, 손석희, 최수종, 정보석 등이 대표적 이미지 이며, 이와 같은 특징으로 인상 좋은 이미지로 명명하였다. 군집 2 는 사교적인, 당당한, 따뜻한, 인상 좋은 이미지가 대표적이며, 얼굴형은 사각형과 둥근형이 많으며, 사각형이라도 각진 윤곽이 딱딱한 느낌은 강하지 않다. 눈썹은 강하지 않으며 눈썹산은 둥글 며 눈은 작은 것이 특징이다. 헤어스타일은 개성 있는 스타일이 다수이며, 개성이 강한 다양한 색과 디자인 슈트가 어울리며 친근 한 이미지가 부각된다. 설운도, 이한위, 최양락, 이경규 등이 대표 적이며, 이와 같은 특징으로 사교적인 이미지로 명명하였다. 군집 3 은 카리스마 있는, 당당한, 강한, 도시적인, 진취적인 이미지가 대표적이며, 얼굴형은 긴형과 사각형이 많으며, 광대가 두드러지 는 형태가 많다. 눈썹은 진하고 강하여 눈매가 날카로운 것이 특 징이다. 헤어스타일은 개성 있는 연출로 다양한 형태이며, 슈트보
다는 캐주얼이 어울리는 카리스마 있는 강한 이미지가 부각된다. 최민식, 최민수, 이동준, 이경영 등이 대표적이며 이와 같은 특징 으로 카리스마 있는 이미지로 명명하였다. 군집 4 는 점잖은, 진취 적인, 우아하지 않는 이미지가 대표적이며, 얼굴형은 긴형과 사각 형, 역삼각형, 타원형 등 다양하고, 눈썹 숱이 적고 형태가 흐릿한 경우가 많다. 눈의 형태는 크지 않으며, 선한 인상이 특징이다. 헤 어스타일은 다소 머리 숱이 적고 전체적으로 뒤로 넘긴 형태이거 나 짧은 형태가 대다수 이다. 편안한 이지 캐주얼이 어울리며 전 반적으로 부각되는 것이 없는 편안한 이미지로 문성근, 신문선, 차범근 등이 대표적이며 점잖은 이미지로 명명하였다.

관련한 선행연구와 비교하면, 실버세대의 여성 이미지 유형을 Oh (2019)의 연구에서 부드러운 스타일, 차분한 스타일, 보수적 인 스타일, 세련된 스타일, 사교적인 스타일로 분류한 것 중에 부 드러운, 차분한, 사교적인 이미지는 이 연구의 유형과 유사한 반 면, 이 연구에서 나타난 카리스마 있는 이미지는 자극물이 남자이 기에 차이가 있는 것으로 사료된다. $\operatorname{Sim}$ (2006)의 연구에서 중년 여성의 자아이미지를 지적 이미지, 사교적 이미지, 세련된 이미 지, 여성스런 이미지, 대담한 이미지로 분류된 것 중에 사교적, 대 담한 이미지는 일부 이 연구의 유형과 유사함을 알 수 있다.

\section{3. 남자 유명인의 퍼스널 이미지에 대한 선호도}

Table 2. Preferences for male celebrities

\begin{tabular}{|c|c|c|c|c|c|}
\hline Rank & Name & Average & Rank & Name & Average \\
\hline 1 & Moon Se Lee & 5.32 & 26 & Bong Won Lee & 4.03 \\
\hline 2 & Ho Jin Cheon & 5.03 & 27 & Byeong Jin Ju & 3.98 \\
\hline 3 & Suk Hee Son & 4.95 & 28 & Si Min Yoo & 3.98 \\
\hline 4 & Sang Won Park & 4.95 & 29 & Beom Keun Cha & 3.98 \\
\hline 5 & Gap Soo Kim & 4.82 & 30 & Byung Se Kim & 3.97 \\
\hline 6 & Yo Seob Hong & 4.80 & 31 & Jin A Tae & 3.95 \\
\hline 7 & Han Wi Lee & 4.78 & 32 & Young Cheol Kim & 3.92 \\
\hline 8 & Gwang Yeol Jeon & 4.70 & 33 & Young Don Lee & 3.92 \\
\hline 9 & Jae Bum Lim & 4.68 & 34 & Dong Jun Lee & 3.90 \\
\hline 10 & Bo Seog Jeong & 4.65 & 35 & Mu Song Lee & 3.77 \\
\hline 11 & Yang Rak Choi & 4.55 & 36 & Kyung Yeong Lee & 3.63 \\
\hline 12 & Su Jong Choi & 4.52 & 37 & Sung Keun Moon & 3.50 \\
\hline 13 & Chang Wan Kim & 4.37 & 38 & Sang Hoon Choi & 3.50 \\
\hline 14 & Jae Duk Sun Woo & 4.35 & 39 & Moon Sun Shin & 3.48 \\
\hline 15 & Min Sik Choi & 4.30 & 40 & Un Do Seol & 3.33 \\
\hline 16 & Young Kyu Park & 4.29 & 41 & Myung Hoon Jung & 3.33 \\
\hline 17 & Suk Woo Kang & 4.27 & 42 & Han Gil Kim & 3.30 \\
\hline 18 & Hong Ryeol Lee & 4.25 & 43 & Hyo Jung Lee & 3.30 \\
\hline 19 & Soo Bae Chul & 4.21 & 44 & Cheol Soo Ahn & 3.25 \\
\hline 20 & Dong Geun Yu & 4.18 & 45 & Seo Bum Hong & 3.10 \\
\hline 21 & Eung Soo Kim & 4.18 & 46 & Hee Do Lee & 3.05 \\
\hline 22 & Jung Woo Choi & 4.15 & 47 & Kyu Chul Kim & 2.95 \\
\hline 23 & Kyoung Kyu Lee & 4.12 & 48 & In Gwon Jeon & 2.65 \\
\hline 24 & Seung Hwan Song & 4.10 & 49 & Jun Pyo Hong & 2.20 \\
\hline 25 & Min Soo Choi & 4.10 & 50 & Hyeong Gi Jo & 1.98 \\
\hline
\end{tabular}


남자 유명인에 대하여 선호도와 선호하는 퍼스널 이미지에 미 치는 영향을 알아보기 위해 기초통계와 회귀분석을 실시하였다.

남자 유명인의 선호하는 이미지를 살펴본 결과는 다음과 같다 (Table 2).

20대 평가자가 가장 선호하는 남자 유명인은 이문세로 나타났 으며, 그 다음으로 천호진, 손석희, 박상원, 김갑수, 홍요섭 순이 다. 가장 싫어하는 남자 유명인은 조형기로 나타났고 그 다음으로 홍준표, 전인권, 김규철, 이희도, 홍서범 순으로 나타났다.

남자 유명인에 대하여 선호하는 퍼스널 이미지에 미치는 영향 을 알아보기 위해 회귀분석을 실시한 결과는 매력적인, 인상 좋 은, 진취적인, 온순한, 따뜻한, 강한, 사교적인, 발랄한, 부드러 운, 개성있는 이미지 순으로 유의한 영향을 미치는 것을 알 수 있 다(Table 3).

남자 유명인의 선호도에 영향을 미치는 이미지를 평균 5 점이상 (반대 이미지일 경우 3 점 이하)을 선정하여 분석하였다(Table 4, $5,6)$.

'매력적인-매력적이지 않는'에서 총 50 명에서 12 명으로 $24 \%$ 를
차지하였고 그 중 매력적인 이미지는 7명(14\%), '매력적이지 않 는'은 5 명 $(10 \%)$ 로 나타났다. 이문세가 가장 매력적이며 그 다음은 김갑수, 임재범, 박상원 등으로 나타났다. 매력적이지 않는 남자 유명인은 홍준표, 조형기, 이희도 순이다.

'인상 좋은-인상 나쁜'에서는 19 명으로 전체의 $38 \%$ 로 차지 하 였고 그 중 인상 좋은 이미지는 14 명 $(28 \%)$, 인상 나쁜 이미지는 5 명(10\%)으로 나타났다. 이문세가 가장 인상 좋은 이미지이며, 그 다음으로 박상원, 최양락, 손석희 등으로 나타났다. 인상 나쁜 이 미지는 전인권, 홍준표, 김규철 순이다.

'진취적인-진취적이지 않는'에서는 총 50 명 중에 6 명으로 $12 \%$ 로 나타났고, 이동준이 가장 진위적인 이미지로 나타났고 그 다음 은 설운도, 이문세, 박상원 순이다.

'온순한-무서운'에서는 총 50 명에서 13 명으로 $26 \%$ 로 나타났고 온순한 이미지는 7 명 $(14 \%)$, 무서운 이미지는 6 명 $(12 \%)$ 를 차지하 였다. 최양락이 가장 온순한 이미지이며 그 다음은 안철수, 홍요 섭, 이문세 등으로 나타났고, 무서운 이미지는 최민식, 전인권, 최 민수 순이다.

Table 3. Influence on personal image preferred for male celebrities

\begin{tabular}{|c|c|c|c|c|c|}
\hline \multirow{2}{*}{ Variable } & \multicolumn{2}{|c|}{ Unstandardized coefficients } & \multirow{2}{*}{$\begin{array}{c}\begin{array}{c}\text { Standardized } \\
\text { coefficients }\end{array} \\
\text { beta }\end{array}$} & \multirow{2}{*}{$t$} & \multirow{2}{*}{$\begin{array}{l}\text { Significance } \\
\text { probability }\end{array}$} \\
\hline & B & standard error & & & \\
\hline Intellectual-Non-intellectual & -0.021 & 0.019 & -0.024 & -1.099 & 0.272 \\
\hline Elegant-Unelegant & 0.047 & 0.021 & 0.051 & 2.195 & 0.028 \\
\hline Chic-Unchic & 0.067 & 0.025 & 0.076 & 2.716 & 0.007 \\
\hline Urban-Countrified & -0.012 & 0.020 & -0.014 & -0.603 & 0.546 \\
\hline Attractive-Unattractive & 0.289 & 0.021 & 0.316 & 13.886 & 0.000 \\
\hline Warm-Cool & 0.068 & 0.021 & 0.075 & 3.295 & 0.001 \\
\hline Strong-Weak & 0.034 & 0.024 & 0.036 & 1.425 & 0.154 \\
\hline Charismatic-Uncharismatic & 0.020 & 0.024 & 0.022 & 0.841 & 0.401 \\
\hline Quiet-Lively & 0.058 & 0.018 & 0.064 & 3.210 & 0.001 \\
\hline Soft-Hard & 0.053 & 0.022 & 0.060 & 2.407 & 0.016 \\
\hline Individual-Non individual & 0.050 & 0.020 & 0.055 & 2.544 & 0.011 \\
\hline Bright-Dark & -0.024 & 0.023 & -0.026 & -1.028 & 0.304 \\
\hline Dignified-Undignified & 0.032 & 0.022 & 0.030 & 1.476 & 0.140 \\
\hline Docile-Dread & 0.101 & 0.024 & 0.110 & 4.160 & 0.000 \\
\hline Good impression-Bad impression & 0.196 & 0.026 & 0.213 & 7.619 & 0.000 \\
\hline Unique-Normal & -0.031 & 0.018 & -0.033 & -1.718 & 0.086 \\
\hline Sociable-Unsociable & 0.058 & 0.022 & 0.057 & 2.643 & 0.008 \\
\hline Pushful-Passive & 0.062 & 0.020 & 0.058 & 3.034 & 0.002 \\
\hline Excited-Calm & 0.024 & 0.019 & 0.026 & 1.264 & 0.207 \\
\hline
\end{tabular}


'세련된-촌스러운'에서는 총 50 명에서 16 명으로 $32 \%$ 를 차지하 였고 세련된 이미지는 7명(14\%), 촌스러운 이미지는 9명(18\%)로 나타났다. 박상원이 가장 세련된 이미지이며 그 다음으로 최수종, 이경영, 전광열 순이고, 촌스러운 이미지는 홍서범, 이희도, 홍준 표 순이다.

'따뜻한-차가운'에서는 총 50 명 중에 12 명으로 $24 \%$ 이고 그 중 따뜻한 이미지는 9 명 $(18 \%)$, 차가운 이미지는 3 명(6\%)로 나타났 다. 최양락이 가장 따뜻한 이미지이며 이문세, 이한위, 김창완의 순이고, 무서운 이미지는 김규철, 최민수, 최민식 순이다.

'강한-약한'은 전체 중에 16 명으로 $32 \%$ 로 나타났고 강한 이미 지는 15 명(30\%), 약한 이미지는 1 명 $(2 \%)$ 이다. 최민식이 가장 강 한 이미지로 나타났고 그 다음은 이동준, 최민수, 이경영 순이며, 가장 약한 이미지는 최양락이다.

'사교적인-사교적이지 않는'에서는 총50명 중에 8 명으로 $16 \%$ 를 차지하고 사교적인 이미지가 8명이다. 가장 사교적인 이미지는 이문세이며, 그 다음은 설운도, 이한위, 최양락 순이다.

'발랄한-점잖은'은 전체 중에 20 명으로 $40 \%$ 를 차지하고, 발랄 한 이미지는 1 명 $(2 \%)$, 점잖은 이미지는 19 명(38\%)이다. 가장 발 랄한 이미지는 최양락이고 가장 점잖은 이미지는 손석희, 최정우,
이경영, 전광열 순이다.

'부드러운-딱딱한'에서는 총 50 명 중에 14 명으로 $28 \%$ 이며, 부 드러운 이미지는 5 명(10\%)로 이문세, 최양락, 박상원, 김창완 순 이며, 딱딱한 이미지는 9 명 $(18 \%)$ 로 최민식, 전인권, 홍준표, 최민 수 순이다.

'개성 있는-개성 없는'은 50명 전체에서 11 명으로 $22 \%$ 를 차지 하고 개성 있는 이미지는 9 명 $(18 \%)$, 개성 없는 이미지는 2 명(4\%) 이며, 가장 개성 있는 이미지는 홍서범이고 그 다음은 임재범, 최 양락, 최민식 순이다. 개성 없는 대표적 이미지는 홍준표, 유시민 순으로 나타났다.

\section{Conclusion}

이 연구에 대한 결과를 요약하고 결론을 내리면 다음과 같다.

첫째, 실버세대 남자 유명인에 대한 퍼스널 이미지에 대한 계층 구조는 강한 이미지와 지적인 이미지가 결합하여 지적인 이미지 로, 따뜻한 이미지와 점잖은 이미지가 결합하여 따뜻한 이미지로 대별되어 최종 실버세대 남자 유명인에 대한 퍼스널 이미지는 지

Table 4. Frequency of male celebrities for image adjectives affecting preference

\begin{tabular}{|c|c|c|c|}
\hline \multicolumn{2}{|c|}{ Variable } & $\mathrm{N}(\%)$ & Total \\
\hline \multirow{2}{*}{ Attractive-Unattractive } & Attractive & $7(14)$ & \multirow[t]{2}{*}{$14(24)$} \\
\hline & Unattractive & $5(10)$ & \\
\hline \multirow{2}{*}{ Good impression-Bad impression } & Good impression & $14(28)$ & \multirow[t]{2}{*}{$19(38)$} \\
\hline & Bad impression & $5(10)$ & \\
\hline \multirow{2}{*}{ Pushful-Passive } & Pushful & $6(12)$ & \multirow[t]{2}{*}{$6(12)$} \\
\hline & Passive & $0(0)$ & \\
\hline \multirow{2}{*}{ Docile-Dread } & Docile & $7(14)$ & \multirow[t]{2}{*}{$13(26)$} \\
\hline & Dread & $6(12)$ & \\
\hline \multirow{2}{*}{ Urban-Countrified } & Urban & $7(14)$ & \multirow[t]{2}{*}{$16(32)$} \\
\hline & Countrified & $9(18)$ & \\
\hline \multirow{2}{*}{ Warm-Cool } & Warm & $9(18)$ & \multirow[t]{2}{*}{$12(24)$} \\
\hline & Cool & $3(6)$ & \\
\hline \multirow{2}{*}{ Strong-Weak } & Strong & $15(30)$ & \multirow[t]{2}{*}{$16(32)$} \\
\hline & Weak & $1(2)$ & \\
\hline \multirow{2}{*}{ Sociable-Unsociable } & Sociable & $8(16)$ & \multirow[t]{2}{*}{$8(16$} \\
\hline & Unsociable & $0(0)$ & \\
\hline \multirow{2}{*}{ Excited-Calm } & Excited & $1(2)$ & \multirow[t]{2}{*}{$20(40)$} \\
\hline & Calm & $19(38)$ & \\
\hline \multirow{2}{*}{ Soft-Hard } & Soft & $5(10)$ & \multirow[t]{2}{*}{$14(28)$} \\
\hline & Hard & $9(18)$ & \\
\hline \multirow{2}{*}{ Individual-Non individual } & Individual & $9(18)$ & \multirow[t]{2}{*}{$11(22$} \\
\hline & Non individual & $2(4)$ & \\
\hline
\end{tabular}


Table 5. Image adjectives affecting preferences for male celebrities (I)

\begin{tabular}{|c|c|c|c|c|c|}
\hline Rank & Attractive & Good impression & Pushful & Docile & Chic \\
\hline \multirow{2}{*}{1} & Moon Se Lee & Moon Se Lee & Dong Jun Lee & Yang Rak Choi & Sang Won Park \\
\hline & 5.73 & 5.98 & 5.37 & 6.08 & 5.72 \\
\hline \multirow{2}{*}{2} & Gap Soo Kim & Sang Won Park & Un Do Seol & Cheol Soo Ahn & Su Jong Choi \\
\hline & 5.43 & 5.93 & 5.30 & 5.28 & 5.35 \\
\hline \multirow{2}{*}{3} & Jae Bum Lim & Yang Rak Choi & Moon Se Lee & Yo Seob Hong & Kyung Yeong Lee \\
\hline & 5.32 & 5.90 & 5.22 & 5.23 & 5.28 \\
\hline \multirow{2}{*}{4} & Sang Won Park & Suk Hee Son & Sang Won Park & Moon Se Lee & Gwang Yeol Jeon \\
\hline & 5.25 & 5.60 & 5.07 & 5.07 & 5.28 \\
\hline \multirow{2}{*}{5} & Su Jong Choi & Su Jong Choi & Suk Hee Son & Han Wi Lee & Moon Se Lee \\
\hline & 5.15 & 5.55 & 5.06 & 5.05 & 5.25 \\
\hline \multirow{2}{*}{46} & Hyo Jung Lee & Min Sik Choi & Han Gil Kim & Kyu Chul Kim & Hyeong Gi Jo \\
\hline & 2.98 & 2.97 & 3.98 & 2.68 & 2.82 \\
\hline \multirow{2}{*}{47} & Cheol Soo Ahn & Hyeong Gi Jo & Byung Se Kim & Hyeong Gi Jo & Bong Won Lee \\
\hline & 2.95 & 2.88 & 3.93 & 2.62 & 2.78 \\
\hline \multirow{2}{*}{48} & Hee Do Lee & Kyu Chul Kim & In Gwon Jeon & Min Soo Choi & Jun Pyo Hong \\
\hline & 2.80 & 2.85 & 3.83 & 2.58 & 2.72 \\
\hline \multirow{2}{*}{49} & Hyeong Gi Jo & Jun Pyo Hong & Jun Pyo Hong & In Gwon Jeon & Hee Do Lee \\
\hline & 2.72 & 2.75 & 3.62 & 2.32 & 2.60 \\
\hline \multirow{2}{*}{50} & Jun Pyo Hong & In Gwon Jeon & Hee Do Lee & Min Sik Choi & Seo Bum Hong \\
\hline & 2.30 & 2.58 & 3.37 & 2.20 & 2.15 \\
\hline
\end{tabular}

Table 6. Image adjectives affecting preferences for male celebrities (II)

\begin{tabular}{|c|c|c|c|c|c|c|}
\hline Rank & Warm & Strong & Sociable & Quiet & Soft & Individual \\
\hline \multirow{2}{*}{1} & Yang Rak Choi & Min Sik Choi & Moon Se Lee & Yang Rak Choi & Moon Se Lee & Seo Bum Hong \\
\hline & 5.78 & 6.40 & 5.75 & 5.13 & 5.69 & 5.80 \\
\hline \multirow{2}{*}{2} & Moon Se Lee & Dong Jun Lee & Un Do Seol & Seo Bum Hong & Yang Rak Choi & Jae Bum Lim \\
\hline & 5.75 & 6.18 & 5.73 & 4.97 & 5.58 & 5.60 \\
\hline \multirow{2}{*}{3} & Han Wi Lee & Min Soo Choi & Han Wi Lee & Jin A Tae & Sang Won Park & Yang Rak Choi \\
\hline & 5.52 & 5.98 & 5.60 & 4.95 & 5.25 & 5.58 \\
\hline \multirow{2}{*}{4} & Chang Wan Kim & Kyung Yeong Lee & Yang Rak Choi & Moon Se Lee & Chang Wan Kim & Min Sik Choi \\
\hline & 5.38 & 5.77 & 5.53 & 4.65 & 5.02 & 5.38 \\
\hline \multirow{2}{*}{5} & Sang Won Park & In Gwon Jeon & Sang Won Park & Han Wi Lee & Seung Hwan Song & Min Soo Choi \\
\hline & 5.13 & 5.75 & 5.37 & 4.60 & 5.00 & 5.30 \\
\hline \multirow{2}{*}{46} & Kyung Yeong Lee & Hong Ryeol Lee & Han Gil Kim & Min Sik Choi & Kyu Chul Kim & Hyo Jung Lee \\
\hline & 3.03 & 3.55 & 3.63 & 2.38 & 2.70 & 3.28 \\
\hline \multirow{2}{*}{47} & Jun Pyo Hong & Hee Do Lee & Min Sik Choi & Gwang Yeol Jeon & Min Soo Choi & Sang Hoon Choi \\
\hline & 3.00 & 3.38 & 3.55 & 2.35 & 2.60 & 3.15 \\
\hline \multirow{2}{*}{48} & Min Sik Choi & Seo Bum Hong & Myung Hoon Jung & Kyung Yeong Lee & Jun Pyo Hong & Jung Woo Choi \\
\hline & 2.90 & 3.17 & 3.50 & 2.30 & 2.48 & 3.12 \\
\hline \multirow{2}{*}{49} & Min Soo Choi & Cheol Soo Ahn & In Gwon Jeon & Jung Woo Choi & In Gwon Jeon & Si Min Yoo \\
\hline & 2.73 & 3.12 & 3.23 & 2.25 & 2.33 & 2.93 \\
\hline \multirow{2}{*}{50} & Kyu Chul Kim & Yang Rak Choi & Jun Pyo Hong & Suk Hee Son & Min Sik Choi & Jun Pyo Hong \\
\hline & 2.50 & 2.50 & 3.17 & 2.23 & 2.25 & 2.52 \\
\hline
\end{tabular}


적인 이미지와 따뜻한 이미지로 나타남을 알 수 있다.

둘째, 실버세대 남자 유명인의 퍼스널 이미지의 유형은 4 개로 구분되었으며, 군집 1 에는 이문세, 박상원 손석희, 최수종 등 16 명 으로 인상 좋은 이미지로, 군집 2 는 설운도, 이한위, 최양락, 이경 구 등 10 명으로 사교적인 이미지로, 군집 3 은 최민식, 최민수, 이 동준, 이경영 등 10 명으로 카리스마 있는 이미지, 군집 4는 문성 근, 신문선, 차범근, 김한길 등 14 명으로 점잖은 이미지로 명명되 었다. 각 유형에 따라 추구하는 퍼스널 이미지를 구현함에 있어 분 석된 특징을 활용한다면 개인 또는 이미지 메이킹 기획에 도움을 줄 수 있을 것이다.

셋째, 남자 유명인 퍼스널 이미지에 대한 20 대의 선호도 순위의 결과는 이문세, 천호진, 손석희, 박상원 순위이며, 싫어하는 순위 는 조형기, 홍준표, 전인권, 김규철 순으로 나타났다. 퍼스널 이미 지 선호에 영향을 미치는 변수는 매력적인, 인상 좋은, 진취적인, 온순한, 따뜻한, 강한, 사교적인, 점잖은, 부드러운, 개성 있는 이 미지 순으로 유의적임을 알 수 있었다. 선호 1 위인 이문세는 매력 적인, 인상좋은, 사교적인, 부드러운 이미지에서 가장 높은 점수를 받은 것으로 보아, 실버세대 남자를 평가하는 20 대의 기준을 이해 할 수 있을 것이다. 반면에 조형기, 홍준표, 전인권 등은 매력적이 지 않은, 인상 나쁜, 사교적이지 않은, 개성 없는 이미지에서 가장 높은 점수로 나타나, 20 대가 비 호감으로 생각한다. 그러므로 20 대의 지지층이 필요한 영역에서 20 대를 공략하기 위한 전략 및 이 미지 메이킹으로 이 연구의 결과를 활용한다면 효과적일 것이다.

마지막으로 이 연구는 평가자의 연령과 지역적 한계가 있음으로 확대 해석에 주의가 필요하다.

\section{Author's contribution}

AKK designed and performed all questionnaire, analyzed data and wrote manuscript.

\section{Author details}

Ae-Kyung Kim (Professor), Institue of Continuing Education, Tongmyong University, 428, Sinseon-ro, Namgu, Busan 48520, Korea.

\section{References}

Huh WW, Hong SK, Han SW, Kim WS. A study about emotional value factors of new silver generation. Design Convergence Study. 11: 3-12, 2012.

Jo SY, Kim JD. A study on the attitude and purchase behaviors for silver generation toward makeup and cosmetics.
Journal of the Korea Society of Cosmetology, 15: 14771492, 2009.

Kim AK. Analysis characteristics of image words shown on the face of woman: women in their 20s and 60s. Fashion \& Textile Research Journal, 14: 465-471, 2012.

Kim AK, Lee KH. A study on the facial color \& shape of an elderly women. Fashion \& Textile Research Journal, 11: 103-111, 2009.

Kim HY, Hahn SW, Hong YJ, Kim YI. Fashion image classification of senior women based on the fashion style, preference color, and self-image. Journal of the Korea Society of Costume, 64: 142-154, 2014.

Kim AK, Oh YK. Study on emotional words and favorableness associated with the faces of women in their 60s. Fashion \& Textile Research Journal, 16: 995-1000, 2014.

Lee ES, Kim SB. A study on the fashion image coordination of modern men. Journal of the Korean Fashion \& Costume Design Association, 14: 93-109, 2012.

Oh YK. Classification and beauty styles analysis according to images of silver generation women celebrities. Asian Journal of Beauty and Cosmetology, 17: 47-56. 2019.

Oh YK, Lee KH. A study on the type analysis and image of the personal style: focused on Korean female entertainers. Journal of the Korea Society of Clothing and Textiles, 30: 137-145, 2006.

Oh YK, Kim AK. Semantic analysis of colors and figures Expressed in the Self-image Drawing of Students of Beauty Majors. Asian Journal of Beauty and Cosmetology, 15: 435-444, 2017.

Seo MR, Kim AK. The use of personal based scenario method for the development of web board game for the pre-elderly. International Journal of Contents, 10: 37-41, 2014.

Sim JH. A study on clothing image evaluation and preference according to self-image classification of the middle-aged women. Journal of the Korean Society of Clothing and Textiles, 30: 1608-1617. 2006.

Song S. The effect of nonverbal cue in televised political debate: an experimental study. Korean Journal of Broadcasting and Telecommunication Studies, 23: 88127, 2009.

Wee HJ, Sohn HS. A study on self-image of the eldery women. Journal of Fashion Business, 5: 117-127, 2001. 


\section{국문초록}

\section{실버세대 남자 유명인의 퍼스널 이미지 유형화 및 선호도 분석}

김애경

동명대학교 평생교육원, 부산, 한국

목적: 이 연구는 실버세대 남자 유명인에 대한 퍼스널 이미지 평가를 통해 유형을 분류하여 그 특성을 살펴보고, 20 대의 실버세대 에 대한 퍼스널 이미지의 선호도 순위를 구체적으로 알아봄으로써 실버세대 남자의 퍼스널 이미지를 이해하고 이미지 메이킹 전략 의 기초자료로 활용하는데 도움을 주고자 한다. 방법: 자극물 대상은 55 세에서 65 세까지의 남자 유명인 50 명을 19 개의 형용사 쌍 과 선호도 문항으로 구성한 설문지를 일대일 대인면접 방식으로 실시하였다. 자료 수집은 2019년 3월 18 일부터 4 월 12 일까지 이루 어졌으며 20 대를 대상으로 최종 200 명의 자료를 분석에 사용하였다. 결과: 첫째, 실버세대 남자 유명인에 대한 퍼스널 이미지에 대 한 계층구조는 지적인 이미지와 따뜻한 이미지로 나타났다. 둘째, 실버세대 남자 유명인의 퍼스널 이미지의 유형은 4 개로 구분되었 으며, 인상 좋은 이미지, 사교적인 이미지, 카리스마 있는 이미지, 점잖은 이미지로 명명하였다. 셋째, 20 대가 가장 좋아하는 남자 유명인 퍼스널 이미지는 이문세, 가장 싫어하는 이미지는 조형기이며, 퍼스널 이미지 선호에 영향을 미치는 변수는 매력적인, 인상 좋은, 진취적인, 온순한, 따뜻한, 강한, 사교적인, 점잖은, 부드러운, 개성 있는 이미지 순이다. 결론: 이 연구에서 각 유형에 따른 분 석된 특징을 바탕으로 추구하는 퍼스널 이미지를 구현한다면, 개인 또는 이미지 메이킹 기획에 도움을 줄 것이다. 20 대의 선호 1 위 는 매력적인, 인상 좋은, 사교적인, 부드러운 이미지에서 가장 높은 점수를 받은 반면에 최하위는 매력적이지 않은, 인상 나쁜, 사교 적이지 않은, 개성 없는 이미지에서 가장 높은 점수로 평가한 결과를 필요한 영역에서 20대를 공략하기 위한 전략으로 활용 한다면 효과적일 것이다.

핵심어: 퍼스널 이미지, 유형, 선호도, 남자 유명인, 실버세대

\section{참고문헌}

김애경. 여성 얼굴에 표출된 이미지 어휘의 특성 분석: 60 대 여성과 20 대 여성을 대상으로. 한국의류산업학회지, 14 : 465-471, 2012.

김애경, 이경희. 노인여성 얼굴색과 얼굴 형태 분석. 한국의류산업학회지, 11: 103-111, 2009.

김희연, 한소원, 홍윤정, 김영인. 시니어 여성의 패션스타일과 선호색 및 자기이미지에 따른 패션이미지 유형화. 복식, $64:$ $142-154,2014$

송석화. TV토론에서 정치인의 비언어적 요소가 이미지, 투표의사에 미치는 영향. 한국방송학보, 23: 88-127, 2009. 심정희. 중년 여성의 자기 이미지 유형화에 따른 의복 이미지 평가와 선호. 한국의류학회지, 30: 1608-1617, 2006.

오윤경. 실버세대 여성유명인의 이미지 유형화 및 미용스타일 분석. 아시안뷰티화장품학술지, 17: 47-56, 2019.

오윤경, 김애경. 뷰티전공 대학생의 자기이미지로 표현된 색과 형태의 의미 분석. 아시안뷰티화장품학술지, 15: 438444, 2017.

오윤경, 이경희. 퍼스널 스타일의 유형 분석과 이미지 연구: 국내여자연예인을 중심으로. 한국의류학회지, 30: 137-145, 2006.

이은숙, 김새봄. 현대 남성의 패션이미지 연출에 관한 연구. 한국의상디자인학회지, 14: 93-109, 2012.

위혜정, 손희순. 노년(老年) 여성(女性)의 자아(自我) 이미지에 관(關)한 연구(研究). 패션비즈니스, 5: 117-127, 2001.

조선영, 김주덕. 실버세대 여성들의 화장에 대한 태도와 화장품 구매행동에 관한 연구. 한국미용학회지, 15: 1477-1492, 2009.

허원회, 홍석기, 한석우, 김원섭. 뉴 실버세대의 감성적 가치 요인에 관한 연구. 디자인융복합연구, $11: 3-12,2012$. 


\section{中文摘要}

\section{银一代男性名人的个人形象类型和偏好分析}

金愛卿

东明大学终生教育院，釜山，韩国

目的: 本研究对个人形象的类型进行了分类, 并通过对韩国银一代男性名人的个人形象评估来检查每种类型的 特征。这项研究旨在了解白银一代男性名人的个人形象, 并利用收集到的信息作为基本数据, 通过评估对白银 一代的个人形象偏爱来制定一种图像制作策略。方法: 选择年龄在55岁至65岁之间的50名男性名人作为评估对 象。问卷由19个形容词对和偏好项组成。数据收集于2019年3月18日至4月12日, 使用了从200名参与者中收集 的最终数据。结果: 首先, 通过聪明而温暖的形象来表明银一代男性名人的个人形象的层次结构。第二, 银一代 男性名人的个人形象有四种类型, 分别是: 良好印象形象, 社交形象, 超凡魅力形象和安静形象。第三, Moon Se Lee拥有20岁男性最喜欢的男性名人个人形象，而Hyung Gi Cho的形象似乎最不受欢迎。结论: 根据每种类 型的分析特征实现个人图像将使人们能够计划其个人图像。20岁最偏好的形象第一位为具有魅力的, 善于交际 的和柔和的形象; 而无吸引力和不良印象, 不善交际和非个人形象排名是最低的。将这一结果用作针对必要地 区的20岁年轻人的策略将会是有效的。

关键词: 个人形象, 类型, 偏好, 银一代, 男性名人 